\title{
Asian summer monsoon rainfall predictability: a predictable mode analysis
}

\author{
Bin Wang $\cdot$ June-Yi Lee $\cdot$ Baoqiang Xiang
}

Received: 26 April 2013/Accepted: 16 June 2014/Published online: 2 July 2014

(C) The Author(s) 2014. This article is published with open access at Springerlink.com

\begin{abstract}
To what extent the Asian summer monsoon (ASM) rainfall is predictable has been an important but long-standing issue in climate science. Here we introduce a predictable mode analysis (PMA) method to estimate predictability of the ASM rainfall. The PMA is an integral approach combining empirical analysis, physical interpretation and retrospective prediction. The empirical analysis detects most important modes of variability; the interpretation establishes the physical basis of prediction of the modes; and the retrospective predictions with dynamical models and physics-based empirical (P-E) model are used to identify the "predictable" modes. Potential predictability can then be estimated by the fractional variance accounted for by the "predictable" modes. For the ASM rainfall during June-July-August, we identify four major modes of variability in the domain $\left(20^{\circ} \mathrm{S}-40^{\circ} \mathrm{N}, 40^{\circ} \mathrm{E}-\right.$
\end{abstract}

B. Wang $\cdot$ B. Xiang

Department of Meteorology and International Pacific Research Center, University of Hawaii, Honolulu, HI 96822, USA

B. Wang

Earth System Modeling Center/NIAMS, Nanjing University of Information Science and Technology, Nanjing 210044, China

J.-Y. Lee $(\bowtie)$

Institute of Environmental Studies, Pusan National University,

Busan 609-735, Korea

e-mail: juneyi@pusan.ac.kr

Present Address:

B. Xiang

University Corporation for Atmospheric Research, Boulder, CO, USA

B. Xiang

NOAA/Geophysical Fluid Dynamics Laboratory, Princeton, NJ, USA $160^{\circ}$ E) during 1979-2010: (1) El Niño-La Nina developing mode in central Pacific, (2) Indo-western Pacific monsoonocean coupled mode sustained by a positive thermodynamic feedback with the aid of background mean circulation, (3) Indian Ocean dipole mode, and (4) a warming trend mode. We show that these modes can be predicted reasonably well by a set of P-E prediction models as well as coupled models' multi-model ensemble. The P-E and dynamical models have comparable skills and complementary strengths in predicting ASM rainfall. Thus, the four modes may be regarded as "predictable" modes, and about half of the ASM rainfall variability may be predictable. This work not only provides a useful approach for assessing seasonal predictability but also provides P-E prediction tools and a spatial-pattern-bias correction method to improve dynamical predictions. The proposed PMA method can be applied to a broad range of climate predictability and prediction problems.

Keywords Asian summer monsoon rainfall - Seasonal predictability - Predictable mode analysis - ENSO .

Monsoon-ocean coupled mode $\cdot$ Physics-based empirical prediction $\cdot$ Multi-model ensemble

\section{Introduction}

Asian summer monsoon (ASM) rainfall provides the major water resources to support over $60 \%$ of the world population and ecosystems, yet seasonal prediction of this variability remains a long-standing challenge (e.g., Kang et al. 2004; Wang et al. 2004, 2005, 2008a, 2009a; Kang and Shukla 2006; Lee et al. 2010, 2011a, b; Sohn et al. 2012 and many others). As shown in Fig. 1, the temporal correlation coefficient (TCC) skill for June-July-August (JJA) 


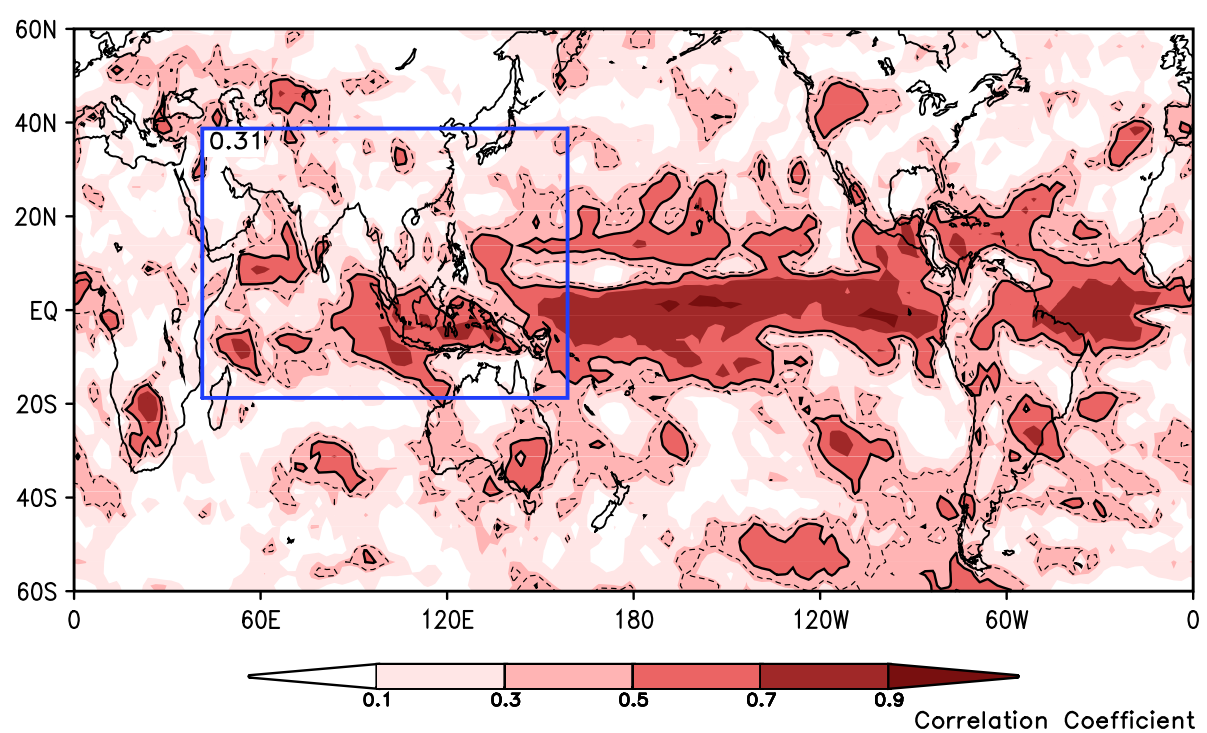

Fig. 1 The temporal correlation coefficient (TCC) skill for JuneJuly-August (JJA) precipitation prediction using the four coupled models' multi-model ensemble (MME) initiated from the first day of June for the 32 years of 1979-2010. The dashed contour is the TCC skill of 0.35 with statistically significance at 0.05 confidence level and the solid contour is the TCC skill of 0.5. Blue box indicates the AsianAustralian monsoon (AAM) region used in this study $\left(20^{\circ} \mathrm{S}-40^{\circ} \mathrm{N}\right.$, $40^{\circ} \mathrm{E}-160^{\circ} \mathrm{E}$ ) and the number in the upper-left corner of the blue box is the averaged TCC skill over the AAM region

of the entire AAM variability using season-reliant SVD analysis of the AAM precipitation and tropical SSTA. They revealed three factors that determine the AAM variability: the remote forcing from the eastern-central Pacific, the offequatorial interaction between atmospheric Rossby waves and underlying dipole SST anomalies, and the regulation of the monsoon annual cycle on the atmospheric response. In a following-up study, Wang et al. (2008b) further found that although the Indian summer monsoon-ENSO relationship has weakened since late 1970s (Kumar et al. 1999), both the East Asian-WNP monsoon and Indonesian monsoon have strengthened their relationship with ENSO (Yun et al. 2010).

Besides ENSO, the Indian Ocean (IO) dipole (IOD) that involves atmosphere-ocean interaction in the IO (Saji et al. 1999; Webster et al. 1999) was also found to play a critical role in affecting the Asian and global climate (Saji and Yamagata 2003; Guan and Yamagata 2003; Ding et al. 2010). In addition, the WNP subtropical High-SST interaction provides a "delayed" impact of ENSO to East Asia (Wang et al. 2000; Lau et al. 2005; Wang et al. 2013b). A similar southeastern IO anticyclone-dipole SST interaction plays an important role in the development and decay of the IOD (Wang et al. 2003; Li et al. 2003).

How to determine the predictable part of total variance and the predictability of seasonal variability using coupled climate models remains an open issue. Several methods have been proposed. Wang et al. (2007) proposed a socalled "predictable mode analysis" (PMA) method to estimate practically potential predictability of seasonal-to- 
interannual climate variability. Different from pure statistical approach, it is an integral approach combining empirical analysis, physical interpretation and retrospective predictions. It produces both physical-based empirical (P-E) forecast and estimation of the predictability. This method has been applied to assess the predictability of the upper-tropospheric circulation anomalies (Lee et al. 2011a; Lee and Wang 2012) and Asian winter monsoon temperature (Lee et al. 2013). The details of the PMA method is described in Sect. 3. Another approach is the mean-square error (MSE) method using multi-model simulations (Kumar et al. 2007). The details of this method are described in Sect. 6 and compared with PMA results. Recently, an optimal projection method was proposed to improve the skill of the dynamical model forecast (Jia et al. 2014). This method uses statistical optimization technique to identify the most skillful or most predictable patterns and then project forecast onto these patterns.

In spite of the considerable progress in understanding the physical factors driving the ASM variability, it remains unclear what the relative contributions of these factors are and to what extent the combination of these factors can predict ASM rainfall variability. How to better estimate predictability limit for monsoon rainfall also remains a difficult and controversial issue.

The major objectives of this study are to identify dominant leading modes of the ASM variability that are potentially most predictable (Sect. 4) and assess the skills for predicting these dominant modes with P-E models and the state-of-the-art dynamical models' MME (Sect. 5). Effort is also made to better estimate seasonal predictability of the ASM rainfall in Sect. 6. Section 7 summarizes major results and discusses limitations of the method.

\section{Data and dynamical models}

Several observed datasets are used in this study, including (1) monthly mean SST from NOAA Extended Reconstructed SST (ERSST, v3b) (Smith and Reynolds 2003); (2) monthly mean precipitation from Global Precipitation Climatology Project (GPCP, v2.2) datasets (Huffman et al. 2009); and (3) monthly mean circulation data from National Centers for Environmental Prediction-Department of Energy (NCEPDOE) Reanalysis 2 products (Kanamitsu et al. 2002). The period from 1979 to 2010 is chosen in this study. Summer (JJA) anomalies are calculated by the deviation of JJA mean from the long-term climatology (1979-2010).

The present study uses four advanced atmosphereocean-land coupled models including NCEP CFS version 2 (Saha et al. 2014), ABOM POAMA version 2.4 (Hudson et al. 2011), GFDL CM version 2.1 (Delworth et al. 2006), and FRCGC SINTEX-F model (Luo et al. 2005). To compare with the P-E forecast, retrospective forecast with early June initial condition was used for the available period of 1979-2010 targeting 0-month lead JJA seasonal prediction. The MME prediction was made by simple average of the four individual models' ensemble mean anomalies after removing their own climatology.

\section{Predictable mode analysis}

The PMA method assumes that a few leading empirical orthogonal function (EOF) modes of interannual variability represent climate signal whereas the rest of higher modes are largely unpredictable noises. Three criteria are proposed to identify most "predictable" modes (Wang et al. 2007). First, the predictable modes together should explain a significant portion of the total variability and be preferably statistically separable from other higher modes. Second, the dynamical origins of these modes should be understood reasonably well. Third, the dynamical models and/or P-E prediction models (Wang et al. 2013b) should be capable of predicting these major modes with fidelity. The emphasis here is to derive the most predictable modes based on observation and physical understanding and then verified by models' hindcast experiments.

The PMA is, therefore, an integral approach combining empirical analysis, physical interpretation and retrospective predictions. The empirical analysis detects most important patterns of variability. The interpretation establishes the physical basis for prediction of the empirical patterns, and thus establishes P-E prediction models. The retrospective predictions (hindcast) with P-E models and/or dynamical models are used to identify the most "predictable" modes. Once predictable modes are identified, the potential predictability can be estimated by the fractional variance accounted for by the "predictable" leading modes by assuming that the predictable modes can be predicted perfectly. One of important advantages of the PMA is to provide not only an estimation of the seasonal predictability but also P-E prediction models and a spatial-pattern-bias correction method to improve dynamical predictions as will be shown in Sects. 5 and 6.

\section{Origins of the major modes of ASM variability}

Two methods are usually used to identify the leading modes: SVD and EOF analysis. The SVD analysis is an effective way to depict co-variability modes between two geophysical fields (Bretherton et al. 1992). However, the SVD modes are not orthogonal and thus difficult to be used for reconstruction of the total variability; additionally, the SVD modes of rainfall and SST can be largely governed by 
(a) EOF1 (21.7\%)

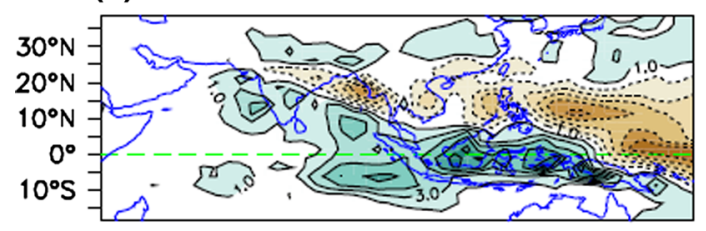

(b) EOF2 (9.5\%)

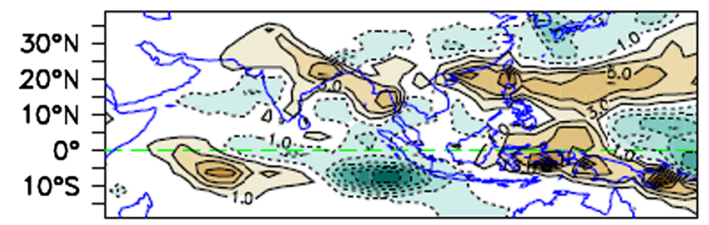

(c) EOF3 (8.5\%)

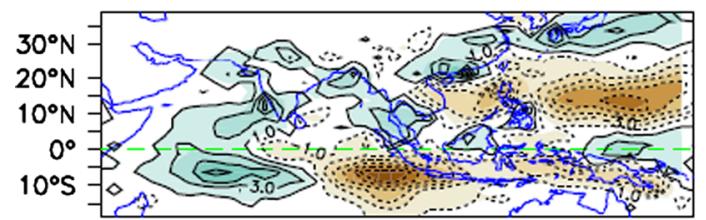

(d) EOF4 (7.3\%)

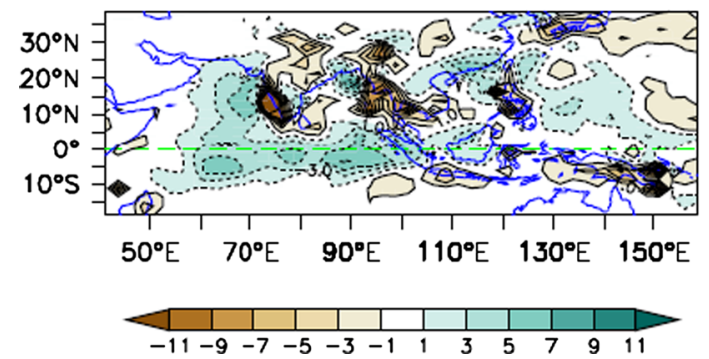

(e) $\mathrm{PC} 1$

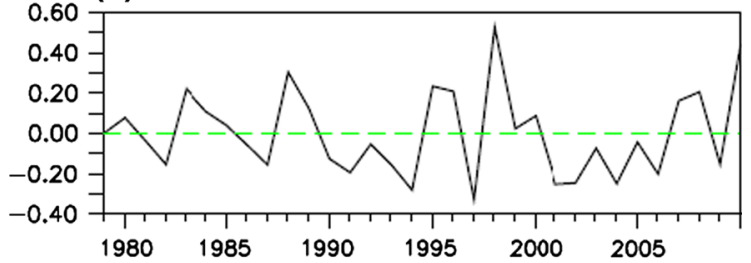

(f) $\mathrm{PC2}$

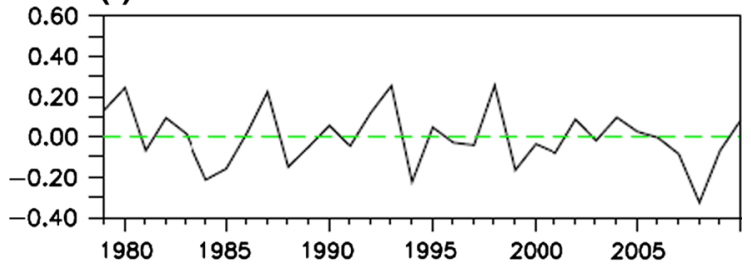

(g) $\mathrm{PC} 3$

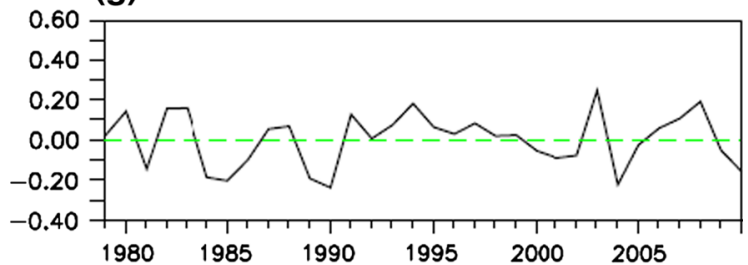

(h) PC4

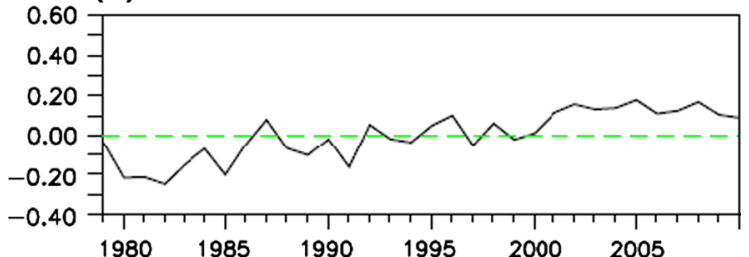

Fig. 2 Spatial distribution of the first four leading EOF modes of JJA precipitation (a-d) and the associated principal components (PC) of each mode (e, f). The GPCP data from 1979 to 2010 were used for the EOF analysis in the entire AAM domain

the SST variability in the tropics not by the rainfall variability. Thus, in this study, we use EOF analysis of rainfall anomaly over the entire AAM region $\left(20^{\circ} \mathrm{S}-40^{\circ} \mathrm{N}, 40^{\circ}-\right.$ $160^{\circ} \mathrm{E}$ ) for the 32 years period of $1979-2010$. The EOF analysis is centered on the hypothesis that the ASM precipitation itself and the derived major modes can be used to reconstruct the total variation of the precipitation without consideration of SSTA.

The four leading EOF modes of the ASM rainfall variability account for about $21.7,9.5,8.5$ and $7.3 \%$ of the total variance, respectively (Fig. 2), and they together can explain about $47 \%$ of the total variance averaged over the AAM monsoon region. To detect the primary large scale drivers for each mode, we made correlation maps of SSTA with reference to each principal component (PC) along with the regressed $850 \mathrm{hPa}$ winds (Fig. 3). The first 4 leading EOF modes of precipitation anomaly are associated with distinct SSTA and wind anomaly patterns.

\subsection{EOF1: ENSO developing mode}

The first EOF mode is characterized by a sharp contrast between prominent suppressed rainfall over the Philippine Sea-equatorial western Pacific and enhanced rainfall over the maritime continent (Fig. 2a). Two branches of increased precipitation are evident in the tropical northern and southern IO due to emanation of low-level low pressure Rossby waves in response to the strong ascent over the maritime continent. Associated with this mode, the overall Indian summer monsoon and East Asian summer Monsoon tend to be in phase; more precipitation over the East Asian subtropical front and the southern and northern India but not in the central India (Ganges River Valley).

The simultaneous correlation map with SST is characterized by prominent SST cooling over the equatorial central Pacific and SST warming over the western Pacific as well as maritime continent (Fig. 3a). The lead/lag correlation maps of SST with reference to the PC1 from the 
(a) Cor with PC1

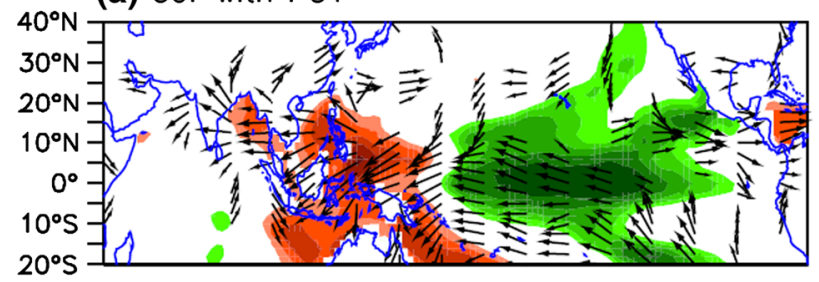

(b) Cor with PC2

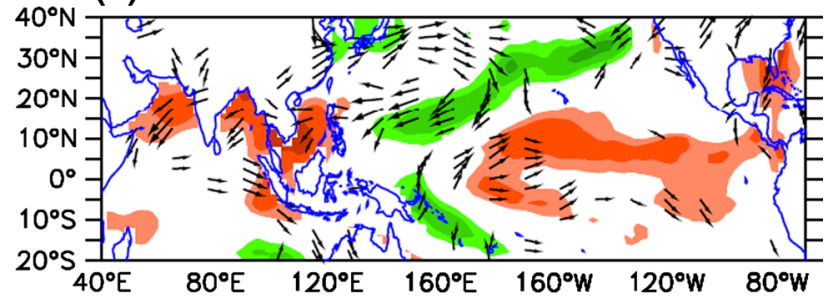

(c) Cor with PC3

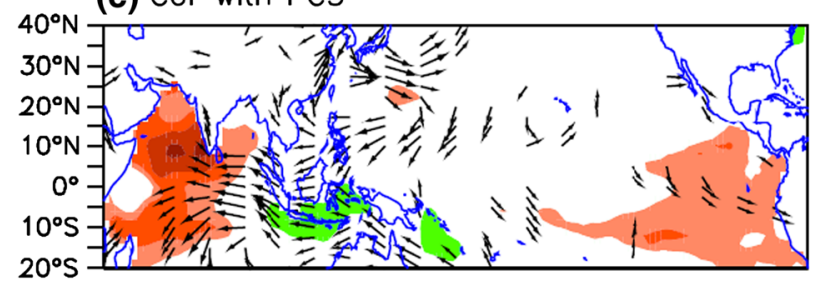

(d) Cor with PC4

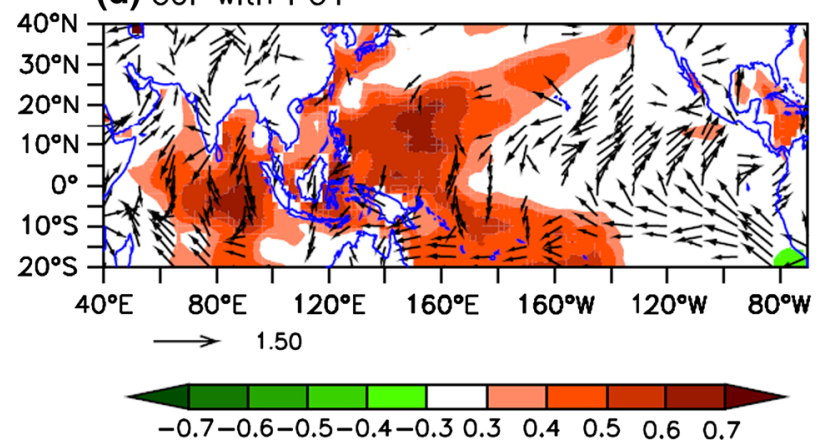

Fig. 3 The corresponding correlation maps of the four modes (ad) with the simultaneous SST and $850 \mathrm{hPa}$ wind anomalies

previous spring to the following winter indicate that the central Pacific cooling signifies a developing La Nina (figure not shown). Thus, we name EOF1 as the ENSO developing mode. How does the developing La Nina induce the EOF 1 precipitation anomalies? The EOF 1 precipitation anomalies are associated with the anomalous WNP anticyclone (WNPAC) (Fig. 3a). The central Pacific cooling can stimulate the anomalous WNPAC by shifting the normal Walker cell, thus reducing convection in the equatorial western Pacific which extends northwestward to South China Sea and northern Bay of Bengal (Fig. 3a). The suppressed western Pacific convection can directly generate the WNPAC by northwestward emanation of descending Rossby waves (Gill 1980). Meanwhile, the central Pacific-induced above-normal precipitation over the maritime continent can also enhance the WNPAC via exciting equatorial Kelvin waves, which generates equatorial easterlies and off-equatorial anticyclonic shear vorticity over the Philippine Sea. With the aid of friction and moisture, this negative vorticity can induce boundary layer divergence, which further suppresses convection and reinforces the WNPAC anomaly (Wang et al. 2013b).

\subsection{EOF2: Indo-western Pacific monsoon-ocean coupled mode}

Differing from the EOF1 mode, the major loading of the EOF2 mode is confined to the western Pacific (Fig. 2b). Precipitation anomaly exhibits a prominent sandwich pattern that consists of enhanced precipitation in the equatorial western Pacific and the Meiyu/Baiu rain bands, and belownormal precipitation over the subtropical WNP. Associated with this mode, the Indian and East Asian Summer Monsoon tend to be out of phase. The rainfall over India is largely suppressed except the Western Ghats, while more precipitation occurs along the East Asian subtropical front zone from Yangtze-Huaihe river valley, to Japan and Korea. The western Japan is most prone to be impacted by this mode with enhanced precipitation, associated with its strong southerly wind component as well as anomalous moisture transport in the northwestern flank of the WNPAC (Fig. 3b).

The precipitation anomaly associated with EOF2 is coupled to the anomalous WNPAC, and the associated SSTA is characterized by a dipolar SSTA anomaly, i.e., the cooling to the southeast of the WNPAC and the warming to the southwest of anticyclone over the northern IO (Fig. 3b). Wang et al. (2000, 2013b) argued that the mean northeasterly winds are important for the maintenance of the WNPAC through the local thermodynamic feedback (i.e., wind-evaporation-SST feedback). Xiang et al. (2013) further pointed out that this mode is not only relying on the background mean flows but also on mean precipitation. Therefore the local atmosphere-ocean feedback can be termed as the convection-wind-evaporation-SST feedback. To the southwest of the anticyclone, the northern IO warming can be a result of the atmospheric forcing associated with the southwestward extension of the WNPAC ridge, while the anticyclone-induced northern IO warming in turn tends to increase local rainfall, which offsets the suppression effect due to remote forcing from the WNPAC. Thus, the atmosphere-ocean interaction and the resultant northern IO warming indirectly contributes to maintenance of the WNPAC (Wang et al. 2013b; Xiang et al. 2013). In brief, this mode is supported by a positive thermodynamic feedback between the WNPAC and underlying Indo-Pacific SSTA dipole over the warm pool. Thus, it is referred to as Indo-western Pacific monsoon-ocean coupled mode. 


\subsection{EOF3: the IOD mode}

The third EOF mode yields the well-known IOD pattern (Saji et al. 1999; Webster et al. 1999) with suppressed precipitation over the southeast tropical IO and enhanced precipitation in the west tropical IO (Fig. 2c). Conspicuously increased precipitation in the South Asian monsoon trough region extends from the Indian subcontinent to southeastern China (Fig. 2c). Given that this mode becomes more intense and frequent especially during the recent decades (Abram et al. 2008), it may play an increasing important role in shaping the East Asian climate.

The SSTA associated with EOF3 shows an apparent SST dipole pattern in the IO which is cohesive with the dipolar precipitation anomaly (Fig. 3c), suggesting that the emerging IOD may be the source of this mode. The time series of this mode have a good correlation with the modified IOD index $(r=0.77)$. The latter is defined by the SSTA difference between the southeastern IO $\left(\mathrm{Eq}-10^{\circ} \mathrm{S}\right.$, $\left.90^{\circ}-130^{\circ} \mathrm{E}\right)$ minus central-western IO $\left(10^{\circ} \mathrm{S}-10^{\circ} \mathrm{N}, 60^{\circ}-\right.$ $80^{\circ} \mathrm{E}$ ), which is slightly different from that used by Saji et al. (1999). The majority of the extreme cases of this mode, such as year 1983, 1991, 1994, 1997, 2003, 2007, 2008, are consistent with the IOD positive phases (Fig. 2g).

Previous studies have extensively examined how the IOD affects Asian and global climate (e.g., Saji and Yamagata 2003; Guan and Yamagata 2003). One possible explanation for the enhanced South Asian precipitation is attributed to the meridional asymmetry of the monsoonal easterly shear during boreal summer, which can particularly strengthen the northern branch of Rossby wave response to the southeastern IO SST cooling, leading to an intensified monsoon flow as well as convection (Wang and Xie 1996; Wang et al. 2003; Xiang et al. 2011). Strikingly, a simultaneous suppressed precipitation is found over the WNP, with the excited anomalous high center over its northwest near the southeastern China (Fig. 2c). We argue that a key system that bridges this relatively weak WNPAC and the IOD is the IOD-induced diabatic heating over South Asia and its adjoining areas.

\subsection{EOF4: the trend mode}

The fourth mode represents an increasing trend of precipitation over the equatorial IO, Arabian Sea, and South China but a decreasing trend over the Western Ghats of India and western part of Indochina Peninsula (Fig. 2d, h) associated with a warming in global tropics especially the Indian and western Pacific Oceans (Fig. 3d). Recent studies have shown that the ASM (as well as entire Northern Hemispheric summer monsoon) rainfall has been intensified during the recent few decades (e.g., Wang et al. 2013a) and the intensification may continue under future global warming according to the projection by coupled models that participated in the phase five of Coupled Model Intercomparison Project (e.g., Lee and Wang 2014; Lee et al. 2014; Wang et al. 2014).

\section{Prediction of the major modes}

In this section, we assess to what extent the four major modes of the ASM variability can be predicted by a P-E model and the state-of-the-art coupled models.

\subsection{Prediction procedure}

There are two steps for prediction of the ASM rainfall variability. First, the four PCs are predicted, separately, by using a set of P-E models (Sect. 5.2) and multi-coupled models' ensemble (Sect. 5.3). We also attempted to build a hybrid P-E-dynamical prediction for each PC by combining the $\mathrm{P}-\mathrm{E}$ and dynamical prediction with equal weight (Sect. 5.4). Second, we reconstruct the forecast fields of ASM rainfall anomaly using linear combination of the observed four EOFs' spatial-pattern and the predicted PCs.

\subsection{Prediction of ASM rainfall with $\mathrm{P}-\mathrm{E}$ models}

A P-E prediction model is made for each PC using linear regression method. Figure 4 shows how to select predictors for each PC. Following Wang et al. (2013b), two predictors are used for PC1: May-minus-March SSTA over the central Pacific (Fig. 4a) and April-to-May mean North Atlantic Oscillation (NAO) index. The PC2, PC3 and PC4 used only one predictor for each: They are, respectively, the April-toMay mean zonal SSTA contrasts between Indian Ocean and WNP (Fig. 4b), the May-minus-March zonal SSTA difference between the western Indian Ocean and Maritime continent (Fig. 4c), and the January-to-May mean SSTA over the Indo-Pacific warm pool region (Fig. 4d). The cross validation method was used to derive the model and make an independent retrospective forecast (Michaelsen 1987). To avoid over-fitting problem, we leave 3 years out progressively centered on a forecast target year from the period 1979-2010 to train the model using data of the remaining years and then apply the model to the forecast years.

Red-dashed lines in Fig. 5 are the predicted PCs by the $\mathrm{P}-\mathrm{E}$ models in the cross-validated mode. The P-E models are capable of capturing the observed PCs with the significant TCC skills of $0.62,0.72,0.60$ and 0.68 for the four PCs, respectively. Thus, to a large extent we can regard the four major modes as the predictable modes. It is worth 
(a) Cor (EOF1 \& May-Mar SSTA)

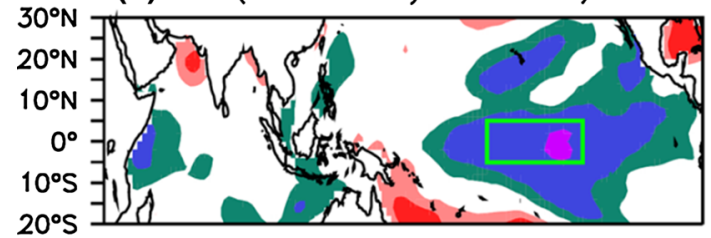

(b) Cor (EOF2 \& AM SSTA)

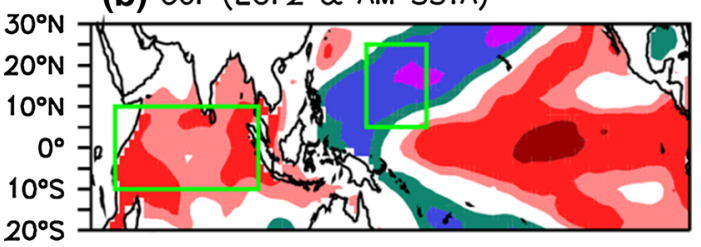

(c) Cor (EOF3 \& May-Mar SSTA)

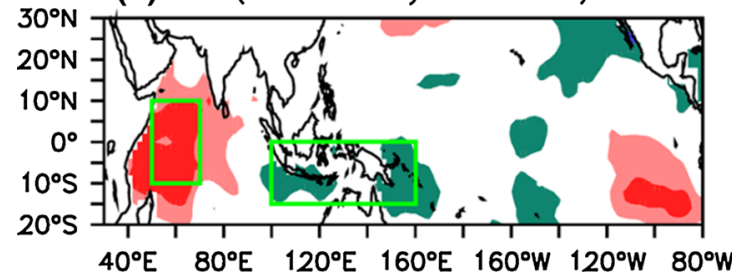

Fig. 4 Selection of predictors based on the correlation maps between a EOF1 and May-minus-March SST anomaly (SSTA), b EOF2 and April-May mean SSTA, c EOF3 and May-minus-March SSTA,

mentioning that the skill scores for prediction of the PCs are cross-validated but the EOF analysis was applied to the entire period. Thus, the cross validation method used here is not totally free from over-fitting.

Applying a linear combination of the predicted four PCs and the observed EOFs, we can predict precipitation anomalies over the entire AAM region. Figure 6a shows the spatial distribution of the forecast skill calculated by the TCC between the observed total field (including all modes of variability) and the reconstructed prediction field just using the first four EOF modes. The significantly high skill is found over India, some parts of Middle East, Philippine, the Maritime Continent, and the WNP. Over the East Asian monsoon region, the skill is still limited. The area-averaged TCC skill for the entire ASM domain is 0.36 .

Figure 7 shows the time series of the pattern correlation coefficient (PCC) skill for each year obtained using the P-E model. The long-term mean of the PCC skill is 0.42 . The PCC skill shows large year-to-year variation with high skills (over 0.6) in 1980, 1982, 1984, 1990, 1994, 1998, 2008 and 2010, and low skills (below 0.2) in 1989, 1996, 1997, 2000, 2003 and 2005. Future studies are required to understand what causes the failure of prediction in these low skill years.

\subsection{The dynamical models' prediction}

It has been noticed that dynamical climate models tend to exhibit significant errors in capturing special distribution of

\section{(d) Cor (EOF4 \& JFMAM SSTA)}

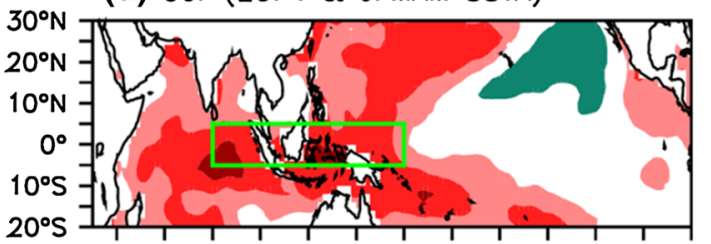

(e) Cor (NAOI \& May-Mar SSTA)
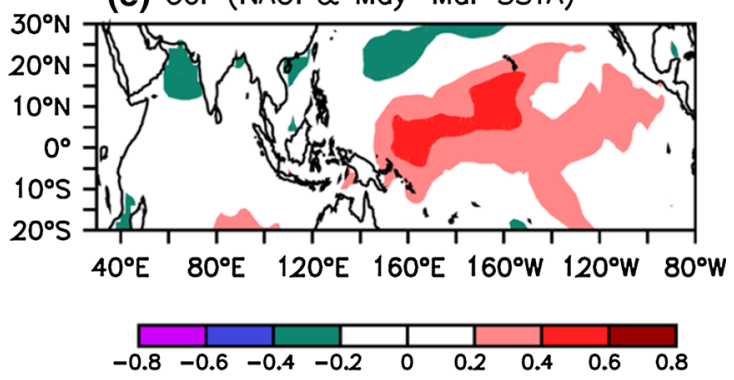

d EOF4 and January-May mean SSTA, and e April-May mean North Atlantic Oscillation index (NAOI) and May-minus-March SSTA. The green box is the area used for defining predictors

major modes of variability. Note that a slight shift of the special pattern of variability in models can result in a substantial drop in skill scores (e.g., Kang et al. 2004). Lee et al. (2011a, 2013) also showed that coupled models have considerable spatial errors in capturing the major EOF modes of upper-tropospheric circulation and Asian winter monsoon temperature variability, respectively. Thus, in this study, we use models' MME predicted four PCs and the corresponding observed EOF patterns to make predictions. This is equivalent to making a spatial-pattern bias correction for the dynamical prediction. As shown by the midblue dashed line in Fig. 5, the MME predicts the first three PCs with high fidelity but has difficulty in capturing the increasing trend of the PC4. The TCC skills for the four modes are $0.80,0.68,0.70$ and 0.32 , respectively.

Figure $6 \mathrm{~b}$ shows the TCC skill for the hindcast precipitation anomaly at each grid using the spatial patterns of the observed EOFs and the predicted PCs by the MME. In general, high skill is found over the tropical monsoon region south of $25^{\circ} \mathrm{N}$. It is further noted that the hindcast with the MME's four PCs and the corresponding observed EOFs (0.39) has better skill than the MME's original skill (0.31) as shown in Fig. 1, suggesting the effectiveness of correcting the biases in the models' EOF spatial patterns. The spatial similarity between the Figs. 1 and $6 \mathrm{~b}$ indicates that the coupled models' MME skill basically comes from the skill in prediction of the first four major modes of interannual variations. 
Fig. 5 The corresponding PC of the first four EOF modes (ad) in observation (OBS), empirical prediction (EmpM), Multi-Model Ensemble (MME) dynamical prediction, and hybrid empirical-dynamical prediction (COM) from 1979 to 2010. The numbers within the parenthesis in the figure legend indicate the TCC between the observed and predicted PC (a) PC1

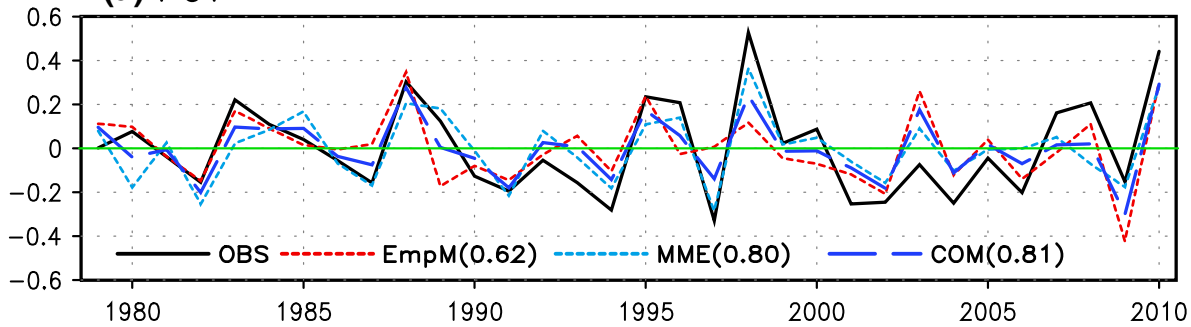

(b) PC2

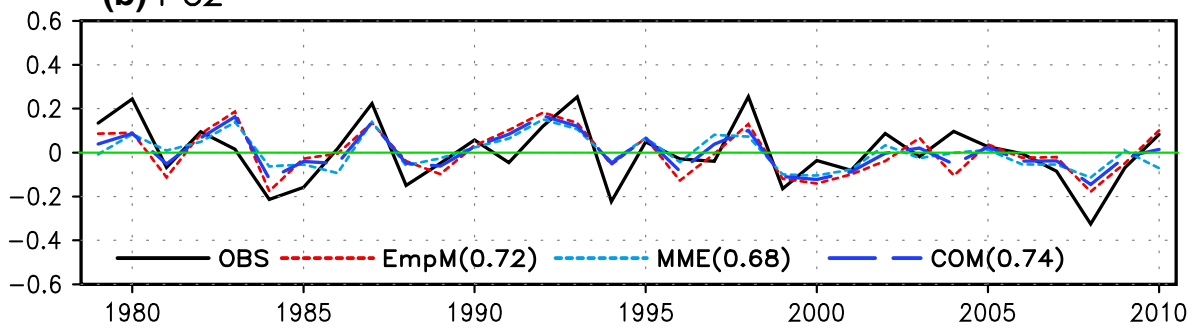

(c) PC3

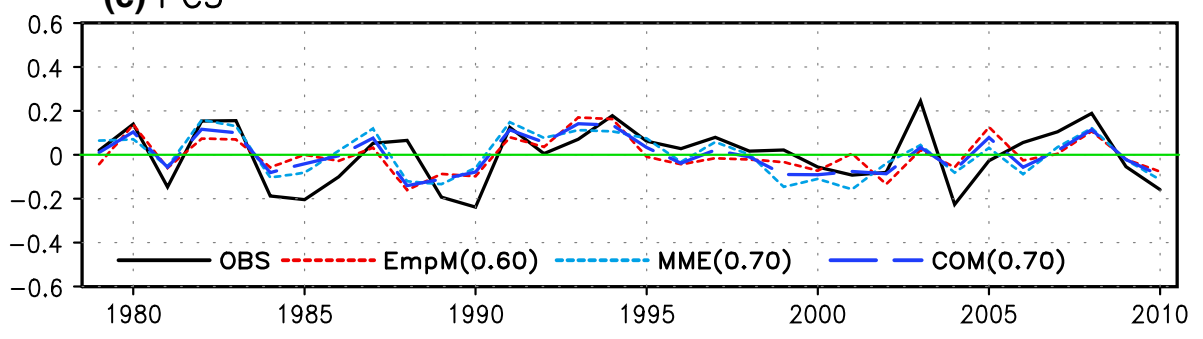

(d) PC4

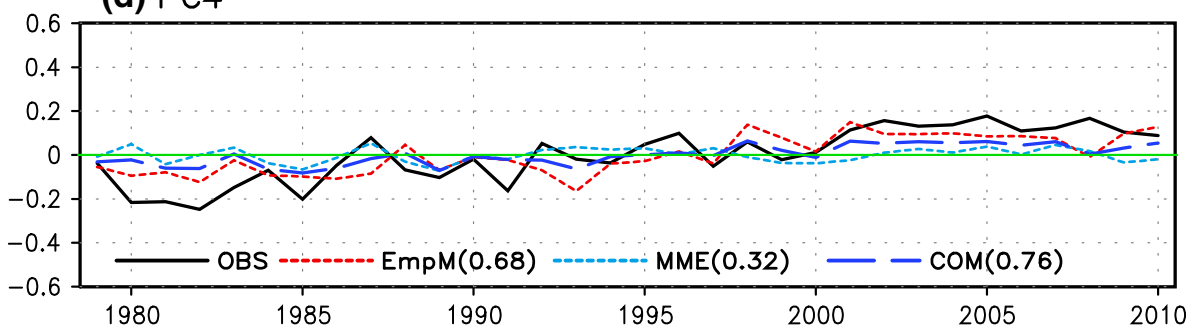

Figure 7 shows the PCC skill for the hindcast precipitation anomaly using the MME. The dynamical approach has the high skill over 0.6 in 1984, 1990, 1994, 1998, 2004 and 2010 but completely fails to predict in 1979, 1980, 1986 and 2006. The long-term mean of the PCC skill is 0.43 .

\subsection{The hybrid empirical-dynamical prediction}

It is noted that the MME has better skills for the first and third PCs whereas the P-E model has better skills for the second and fourth PCs, thus they are complimentary to each other, providing a potential to improve the ASM rainfall prediction by combining them together. The blue longdashed lines in Fig. 5 are the predicted PCs by combining the P-E and dynamical prediction with equal weight. The combined prediction has generally better skill than each method alone. Figure 7 shows that the PCC skill of the hybrid prediction (0.49) is higher and more stable than those of individual empirical and dynamical model predictions (0.42 and 0.43 , respectively). The hybrid P-E and dynamical prediction may be more useful than individual predictions particularly over land regions of the AAM (Fig. 6c). Note that use of weighted hybrid model can have better skill but there is no guarantee that the weighting method is better for actual prediction due to potentially over-fitting.

Although the hybrid model has a useful skill for the AAM rainfall in general, prediction for land monsoon rainfall, especially over the East Asian region, is still limited. Figure 8 shows the normalized anomalies of Indian summer monsoon rainfall (ISMR), East Asian summer monsoon rainfall (EASMR), and WNP summer monsoon rainfall (WNPSMR) obtained from observation, P-E model, dynamical model prediction, and the hybrid 
Fig. 6 The TCC skill for JJA precipitation prediction using the a P-E model (EmpM), b MME's first four modes (MME4M), c hybrid empiricalE-dynamical model (COM), and d the observed first four modes (OBS4M). For the observed reference field, total anomaly (i.e., all modes of variability) is used whereas the predicted field is reconstructed just by the first four EOF modes. The dashed contour is the TCC skill of 0.35 with statistically significance at 0.05 confidence level and the solid contour is the skill of 0.5 . The number in the upper-left corner of each panel indicates the averaged TCC skill over the entire region

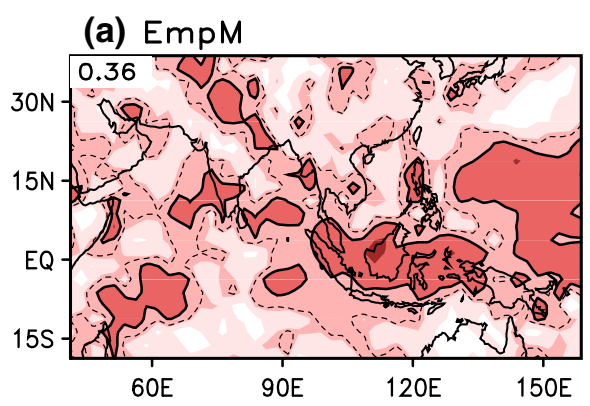

(b) MME4M

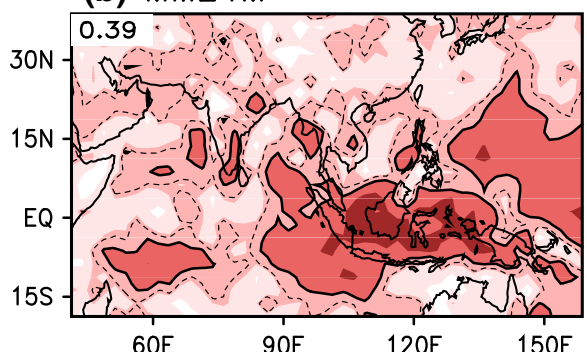

(c) $\mathrm{COM}$

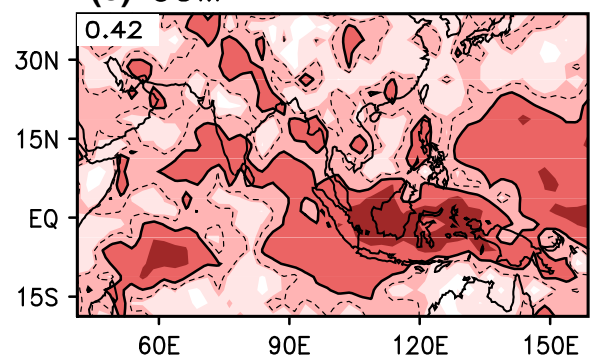

(d) OBS4M

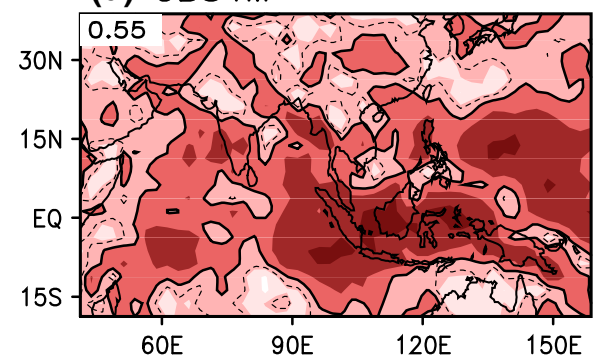

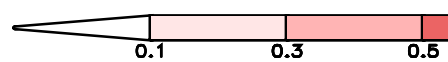

0.9 Correlation Coefficient

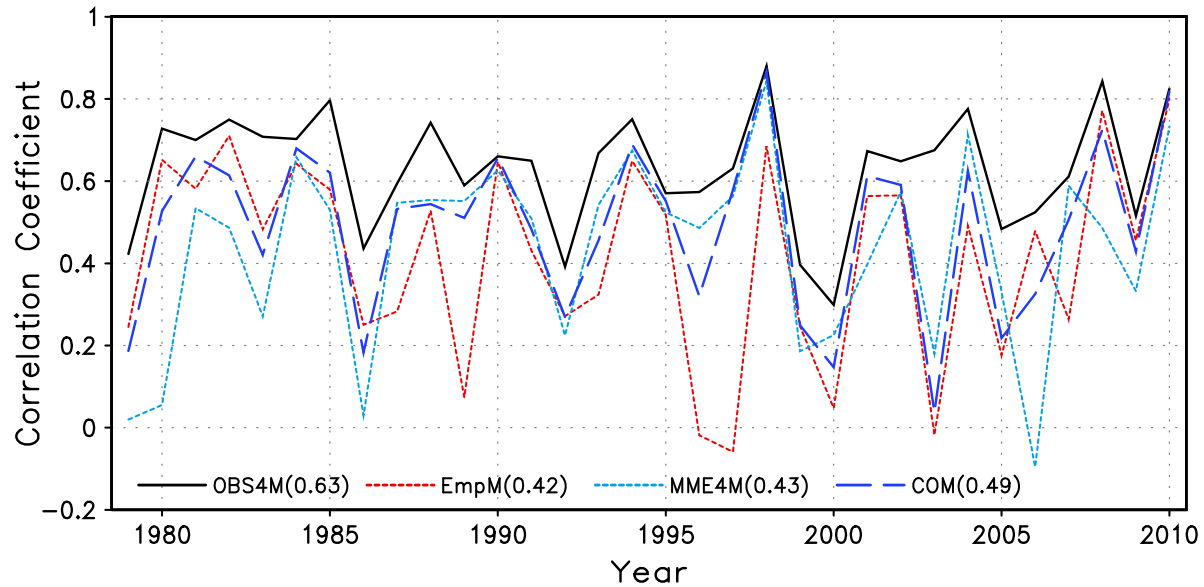

Fig. 7 The pattern correlation coefficient (PCC) skill for JJA precipitation prediction as a function of forecast year using 3-year out cross-validated empirical prediction $(\mathrm{EmpM})$, prediction with the MME's 4 modes (MME4M), and the hybrid empirical-E-dynamical

prediction. The ISMR and EASMR are averaged in the land region over $7.5^{\circ}-27.5^{\circ} \mathrm{N}, 70^{\circ}-90^{\circ} \mathrm{E}$ and $22.5^{\circ}-40^{\circ} \mathrm{N}$, $110^{\circ}-140^{\circ} \mathrm{E}$, respectively. The WNPSMR is averaged in the entire region over $5^{\circ}-20^{\circ} \mathrm{N}, 110^{\circ}-160^{\circ} \mathrm{E}$. The hybrid model has a high skill for the WNPSMR $(r=0.68)$ and a useful skill for the ISMR $(r=0.49)$ but a low skill for the EASMR $(r=0.26)$. It is further noted that the dynamical models' MME has a better skill for the WNPSMR but the P-E model has a better skill for the land monsoon rainfall (ISMR and EASMR). It suggests that well-designed P-E models are still useful for improving seasonal prediction of land rainfall as demonstrated by several recent studies for prediction $(\mathrm{COM})$ over the entire AAM region. The potential attainable forecast skill using observed four PCs (OBS4M) is also compared. The numbers within the parenthesis in the figure legend indicate the averaged PCC skill over the 32 years

ISMR (e.g., Rajeevan et al. 2007), for EASMR (e.g., Sohn et al. 2012; Wang et al. 2013b) and for the South China monsoon (e.g., Yim et al. 2014).

\section{Predictability of the ASM rainfall}

6.1 The potentially attainable forecast skill estimated by the PMA

Given the fact that the first four EOF modes can be skillfully predicted by the hybrid P-E and dynamical model, we 
Fig. 8 The normalized anomalies of a Indian summer monsoon land rainfall (ISMR), b East Asian summer monsoon land rainfall (EASMR), and c Western North Pacific summer monsoon rainfall (WNPSMR) obtained from observation, empirical-E forecast (EmpM), dynamical forecast (MME), and the combined P-E-dynamical forecast (COM). The numbers within the parenthesis in the figure legend indicate the TCC between the observed and predicted PC (a) ISMR (land only)

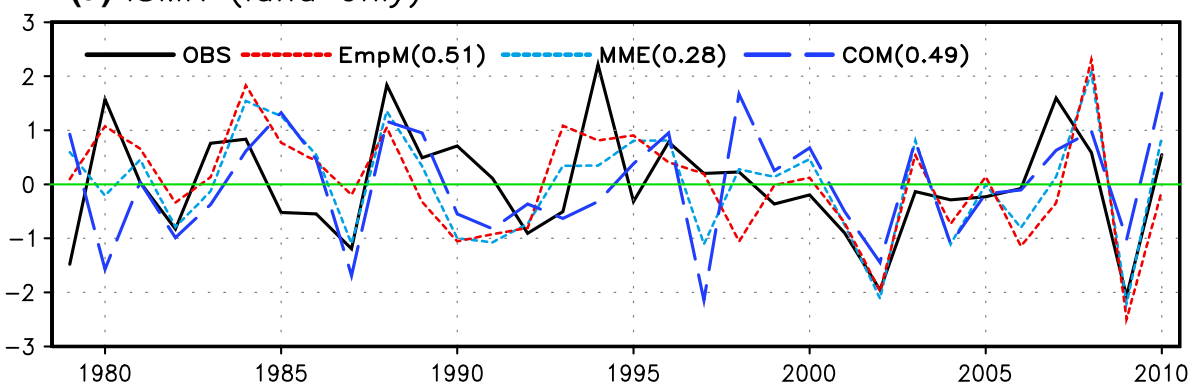

(b) EASMR (land only)

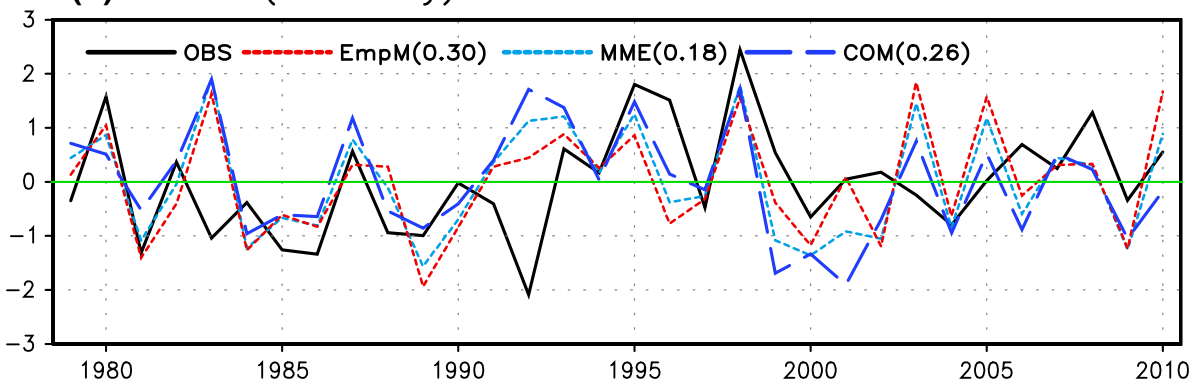

(c) WNPSMR

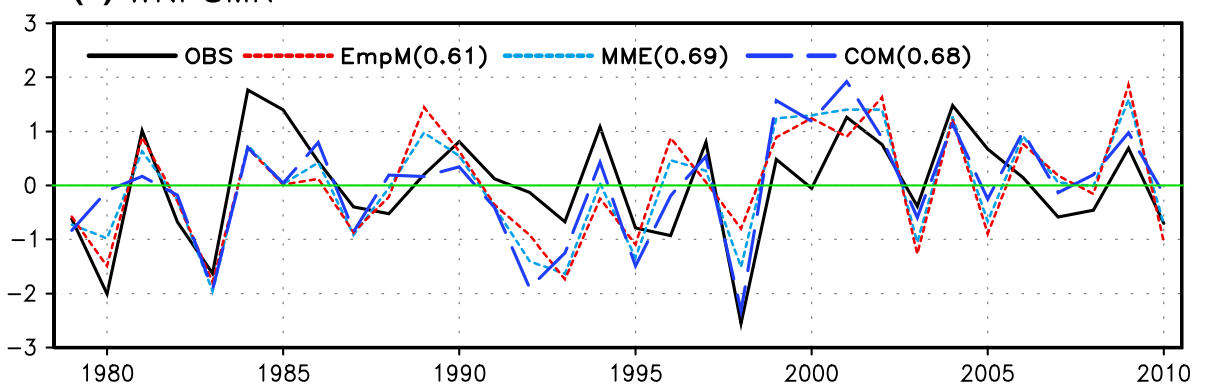

may estimate the potential attainable forecast skill for the ASM rainfall using these most predictable modes. The observed predictable part is reconstructed by the linear combination of the first four predictable EOF modes. Here we consider all EOF higher than the 4th mode as noise parts mainly because these higher modes have small fractional variances of $<5 \%$ and these modes are difficult to interpret and predict. Assuming that the first four modes can be predicted perfectly, the potentially attainable forecast skill can be obtained from the correlation between the observed total field and the reconstructed predictable part (Refer Sect. 2.3 of Lee et al. 2013 for detail formulation).

Figure $6 \mathrm{~d}$ shows the attainable TCC skill estimated by the PMA. The area-averaged potentially attainable skill is 0.55. It is noted that there are still rooms to improve the ASM rainfall prediction by improving the predictions of the first four PCs, particularly over land region of the AAM and East Asian monsoon region. Figure 7 further shows the attainable PCC skill (black solid line) as a function of forecast year. It is shown that the hybrid prediction reaches the attainable skill in some years including 1990, 1998 and
2010. In general, the hybrid prediction has higher skills when the attainable skill is higher. However, the hybrid prediction has significantly less skill in some years than attainable skill such as 1986, 2003 and 2005.

\subsection{Comparison of the two approaches for estimation of the ASM rainfall predictability}

We have shown that the first four EOF modes are largely predictable with the dynamical and empirical models. The four modes together account for about $47 \%$ of the total interannual variance averaged over the AAM monsoon region in observations. This portion of the variation may be considered as the predictable part of the precipitation variability, because the dynamic models' MME and P-E models can capture these four major modes reasonably well but cannot skillfully capture the rest of the higher modes. This suggests a new approach to estimate the practical predictability of the tropical seasonal precipitation in coupled climate models; i.e., we can quantify the "predictability" by the fractional variance that is accounted 
(a) PMA

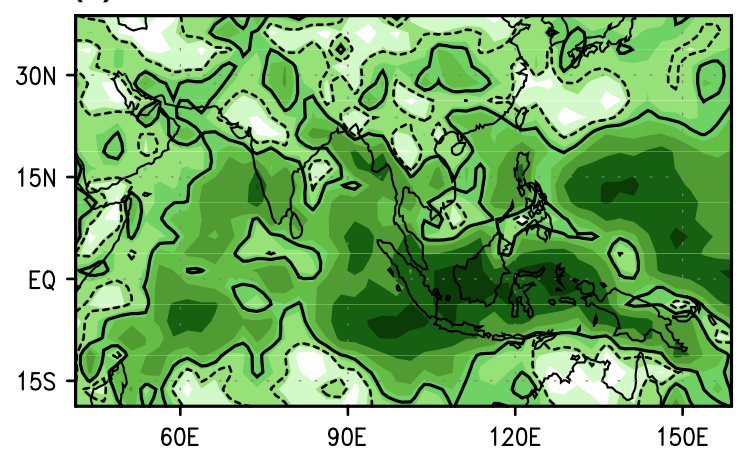

(b) MSE

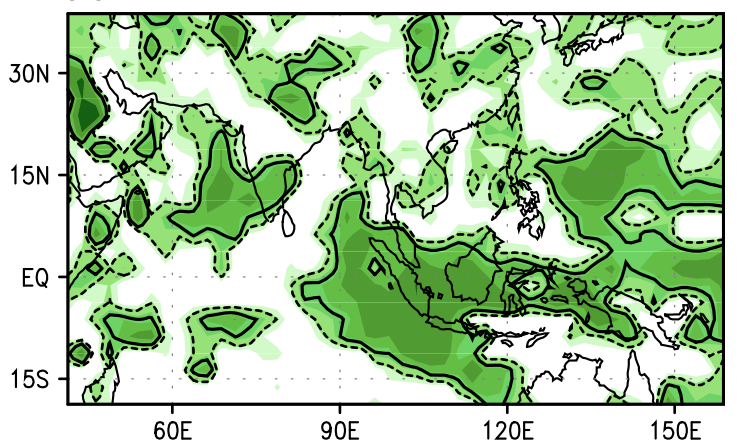

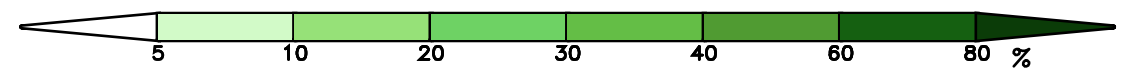

Fig. 9 Fractional signal variance (the predictable part of total variance) obtained from a predictable mode analysis (PMA) using the observed four EOF modes and $\mathbf{b}$ mean-square error (MSE) method using multiple dynamical model predictions for the 32 years of 1979-2010. The dashed (solid) contour represents $12 \%$ (25\%) that are corresponding to the TCC of $0.35(0.5)$ for by the sum of the most "predictable" modes in the observations.

Figure 9a shows fractional signal variance estimated by the PMA approach. Over the equatorial and subtropical monsoon region, more than $40-60 \%$ of total variability can be predictable but the fractional signal variance over the East Asian summer monsoon region is only about $15-20 \%$.

Another approach is the MSE method using multi-model simulations previously suggested by Kumar et al. (2007). They found that the expected value of the MSE of the ensemble mean prediction using a single model can be decomposed into three terms: the observed noise variance, the noise variance of the ensemble mean of dynamical model's simulation, and model's systematic errors associated with the signal variance. For large ensembles and a dynamic model with no systematic error, MSE equals the observed noise variance. However, the MSE for the ensemble mean of dynamical model simulations is always larger than the observed noise variance. It is obvious that different models have different MSEs at each geographical location and the smaller MSE is closer to the true value of observed noise variance. Thus, the optimal estimate of the noise variance can be obtained from the smallest MSE among many models' results at each geographical location. The signal variance can be estimated by subtracting the smallest MSE (which is the estimated internal variance) from the observed total variance.

Figure $9 \mathrm{~b}$ shows the fractional signal variance estimated by the MSE method using the four coupled models. It is noted that the predictability estimated by the MSE is significantly less than that by the PMA, probably due to the large systematic errors of the current coupled models in predicting the boreal summer precipitation. Since internal variance estimated by the MSE includes models' systematic errors by definition, the MSE estimation strongly depends on the quality and numbers of the models being used. The comparison between the PMA and MSE approach in estimating the ASM rainfall predictability indicates that the PMA may be a more useful tool for the estimation of potential predictability.

\section{Summary and discussion}

We have identified four major modes of ASM rainfall variability and discussed their respective causes of the variability. The four modes are ENSO developing mode in central Pacific, Indo-western Pacific monsoon-ocean coupled mode, IOD and warming trend mode, which can explain about $47 \%$ of the total variance in the AAM domain (Figs. 2, 3, 4). These findings provide dynamical insights about the physical processes that control the ASM rainfall variability and their relative contributions to the total variability of the ASM rainfall.

We have also shown that the four modes can be, to a large extent, predictable with the P-E models and with the MME of four state-of-the-art dynamical models (Fig. 5). The four models' MME has a better skill for the first and third modes while the P-E model has a better skill for the second and fourth mode. The two approaches are thus complimentary, providing a potential to improve the ASM rainfall prediction by combining the $\mathrm{P}-\mathrm{E}$ model and dynamical predictions (Fig. 6). The combined dynamicalP-E prediction model (by equal weighting) obtains a 32-year averaged pattern correlation skill of 0.49 (Fig. 7). The combined hybrid model has a high skill for the WNPSMR with the temporal correlation skill $(r)$ of 0.68 
(a) MME with all modes

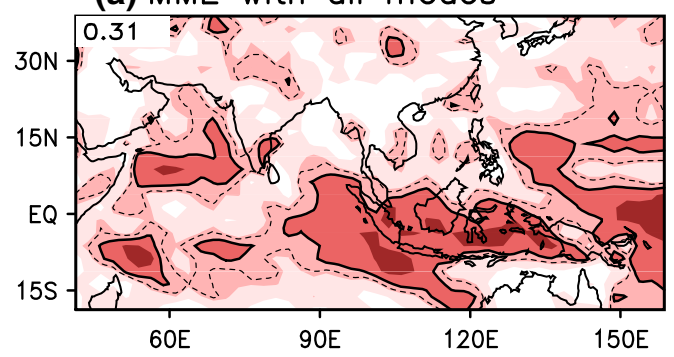

(b) MME with first four

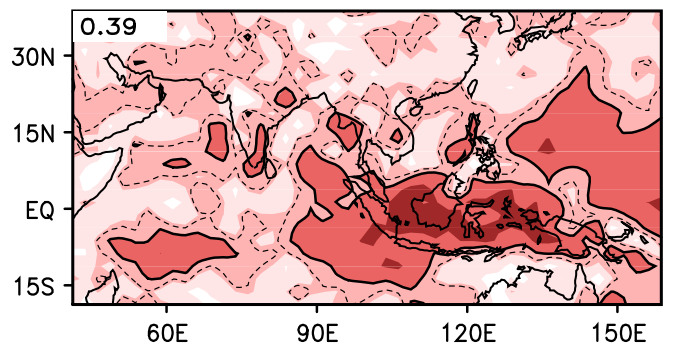

(c) MME with residual modes

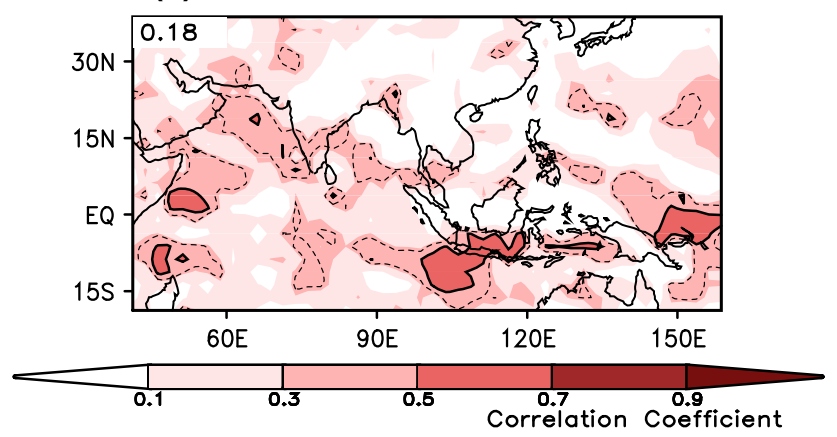

Fig. 10 The four dynamical models' MME prediction skill for the ASM rainfall obtained by using a all EOF modes, $\mathbf{b}$ the first four modes, and $\mathbf{c}$ all the rest higher modes

and a useful skill for the ISM land rainfall $(r=0.49)$ but a low skill for the EASM land rainfall $(r=0.26)$. It is also noted that dynamical models' MME has a better skill for the WNPSMR but the P-E model has a better skill for the ISM and EASM land rainfall.

The four major EOF modes of the JJA rainfall anomaly over the entire AAM region are identified as most "predictable" mode for a number of reasons. First, the four modes explain a significant portion of total variability (47\%). Second, the dynamical origins and processes governing the variability of each mode are generally understood. Third, the P-E model and dynamical climate models are capable of predicting the temporal variation of these modes. Results in Fig. 10 indicate that the coupled models' MME skill basically comes from the skill in prediction of the first four major modes of interannual variations and the contribution from the residual higher modes for the MME prediction is insignificant or moderate depending on region (Fig. 10c).
One can estimate the "predictability" by the fractional variance that is accounted for by the sum of all "predictable" modes in the observations assuming that these predictable modes can be perfectly predicted. The PMA estimates that more than $40-60 \%$ of total variability can be predictable over the equatorial and subtropical monsoon region, but the fractional signal variance over the EASM region is only about $15-20 \%$ (Fig. 9a).

The results here show that the PMA may provide a useful approach for estimating the seasonal predictability in comparison to the conventional approach based on dynamical models' ensemble simulation. The conventional MSE approach strongly depends on the quality and numbers of the models being used.

It is worth noting that the predictable modes identified may vary over longer, say multi-decadal, time scales. In addition, the trend mode (Fig. 2h) may play a more important role in future due to increasing greenhouse gases. Thus, the predictability limit may vary not only on interannual time scale (Fig. 7) but also on multi-decadal to long-term time scale. The present work has examined only 0 -month lead predictability. It would be interesting to study the prediction skill as a function of the forecast lead. The recent results also suggest that separate prediction of the early and late summer monsoon precipitation might be more fruitful (Wang et al. 2009c; Rajagopalan and Molnar 2012).

The underlying assumption of the PMA analysis is that a few leading EOF modes of interannual variability represent climate signals whereas the rest of them are unpredictable climate noises. In some cases, the predictable and unpredictable modes are not necessarily separated clearly, which may induce uncertainties in the estimation of the predictability. The most challenging and interesting part of the analysis is physical understanding. It should also be realized that uncertainties exist concerning the identification of predictable modes as identification of the most predictable modes relies on the quality of the dynamical models or P-E models. Since the analysis starts with EOF analysis and the some predictable modes may not be reflected by the leading EOF modes, it is not guaranteed that the method will be identical to the predictable modes.

Acknowledgments This work was supported by APEC Climate Center, and IPRC, which is in part supported by JAMSTEC and NOAA. This work was also funded by the National Research Foundation of Korea (NRF) through a Global Research Laboratory (GRL) Grant (MEST 2011-0021927). We thank Drs. J. Schemm, O. Alves, B. Stern, and J.-J. Luo for providing the hindcast data. The authors appreciate two anonymous reviewers' comments. This is the SOEST publication number 9136, IPRC publication number 1066 and ESMC publication number 6 .

Open Access This article is distributed under the terms of the Creative Commons Attribution License which permits any use, 
distribution, and reproduction in any medium, provided the original author(s) and the source are credited.

\section{References}

Abram NJ, Gagan MK, Cole JE, Hantoro WS, Mudelsee M (2008) Recent intensification of tropical climate variability in the Indian Ocean. Nat Geosci 1:849-953

Bretherton CS, Smith C, Wallace JM (1992) An intercomparison of methods for finding coupled pattern in climate data. J Clim 5:541-560. AIOMFF $>2.0 . \mathrm{CO} ; 2$

Chang CP, Harr PA, McBride J, Hsu HH (2004) Maritime Continent monsoon: annual cycle and boreal winter variability. In: Chang CP (ed) East Asian monsoon. World Scientific Series on Meteorology of East Asia. vol 2, pp 107-150

Delworth TL et al (2006) GFDL's CM2 global coupled climate models-part I: formulation and simulation characteristics. J Clim 19:643-674

Ding Y, Chan JCL (2005) The East Asian monsoon: an overview. Meteorol Atmos Phys 89:117-142

Ding R, Ha KJ, Li J (2010) Interdecadal shift in the relationship between the East Asian summer monsoon and the tropical Indian Ocean. Clim Dyn 34:1059-1071

Gill AE (1980) Some simple solutions for heat-induced tropical circulation. Q J R Meteorol Soc 106:447-462

Guan Z, Yamagata T (2003) The unusual summer of 1994 in East Asia: IOD teleconnections. Geophys Res Lett 30. doi:10.1029/ 2002GL016831

Hudson D, Alves O, Hendon H, Wang G (2011) The impact of atmospheric initialization on seasonal prediction of tropical Pacific SST. Clim Dyn 36:1155-1171

Huffman GJ, Adler RF, Bolvin DT, Gu G (2009) Improving the global precipitation record: GPCP version 2.1. Geophys Res Lett 36:L17808

Jia L, Delsole T, Tipett MK (2014) Can optimum projection improve dynamical model forecast? J Clim 27:2643-2655

Kanamitsu M et al (2002) NCEP-DOE AMIP-II reanalysis (R-2). Bull Am Meteorol Soc 83:1631-1643

Kang I-S, Shukla J (2006) Dynamic seasonal prediction and predictability of the monsoon. In: Wang B (ed) The Asian monsoon. Springer-Paraxis, Chichester

Kang IS, Lee JY, Park CK (2004) Potential predictability of summer mean precipitation in a dynamical seasonal prediction system with systematic error correction. J Clim 17:834-844

Kumar KK, Rajagopalan B, Cane MA (1999) On the weakening relationship between the Indian monsoon and ENSO. Science 284:2156-2159

Kumar A, Jha B, Zhang Q, Bounoua L (2007) A new methodology for estimating the unpredictable component of seasonal atmospheric variability. J Clim 20:3888-3901

Lau K-M, Wu H-T (2001) Principal modes of rainfall-SST variability of the Asian summer monsoon: a re-assessment of monsoonENSO relationships. J Clim 14:2880-2895

Lau N-C, Leetma A, Nath MJ, Wang HL (2005) Influences of ENSOinduced Indo-Western Pacific SST anomalies on extratropical atmospheric variability during the boreal summer. J Clim 18 . doi:10.1175/JCLI3445.1

Lee JY, Wang B (2012) Seasonal climate prediction and predictability of atmospheric circulation. In: Druyan LM (ed) Climate models. InTech Open Access Book, New York, pp 19-42

Lee JY, Wang B (2014) Future change of global monsoon in the CMIP5. Clim Dyn 42:101-119. doi:10.1007/s00382-012-1564-0
Lee JY, Wang B et al (2010) How are seasonal prediction skills related to models' performance on mean state and annual cycle? Clim Dyn 35:267-283

Lee JY, Wang B, Ding Q, Ha KJ, Ahn JB, Kumar A, Stern B, Alves O (2011a) How predictable is the northern hemisphere summer upper-tropospheric circulation? Clim Dyn 37:1189-1203. doi:10.1007/s00382-010-0909-9

Lee SS, Lee JY, Ha KJ, Wang B, Schemm JKE (2011b) Deficiencies and possibilities for long-lead coupled climate prediction of the Western North Pacific-East Asian summer monsoon. Clim Dyn 36:1173-1188

Lee JY, Lee SS, Wang B et al (2013) Seasonal prediction and predictability of the Asian winter temperature variability. Clim Dyn 41:573-587. doi:10.1007/s00382-012-1588-5

Lee JY, Wang B, Seo KH, Kug JS, Choi YS, Kosaka Y, Ha KJ (2014) Future change of Northern Hemisphere summer tropical-extratropical teleconnection in CMIP5 models. J Clim 27:3643-3664. doi:10.1175/JCLI-D-13-00261.1

Li T, Wang B, Chang C-P, Zhang Y (2003) A theory for the Indian Ocean dipole-zonal mode. J Atmos Sci 60:2119-2135

Luo J-J, Masson S, Roeckner E, Madec G, Yamagata T (2005) Reducing climatology bias in an ocean-atmosphere CGCM with improved coupling physics. J Clim 18:2344-2360

Michaelsen J (1987) Cross-validation in statistical climate forecast model. J Clim Appl Meteorol 26:1589-1600

Rajagopalan B, Molnar P (2012) Pacific Ocean sea-surface temperature variability and predictability of rainfall in the early and late parts of the Indian summer monsoon season. Clim Dyn 39:1543-1557

Rajeevan M, Pai DS, Kumar RA, Lal B (2007) New statistical models for long-range forecasting of southwest monsoon rainfall over India. Clim Dyn 28:813-828

Saha $\mathrm{S}$ et al (2014) The NCEP climate forecast system version 2. J Clim 27:2185-2208

Saji NH, Yamagata T (2003) Possible impacts of Indian Ocean dipole mode events on global climate. Clim Res 25:151-169

Saji NH, Goswami BN, Vinayachandran PN, Yamagata T (1999) A dipole mode in the tropical Indian Ocean. Nature 401:360-363

Smith TM, Reynolds RW (2003) Extended reconstruction of global sea surface temperature based on COADS data (1854-1997). J Clim 16:1495-1510

Sohn S-J et al (2012) Assessment of the long-lead probabilistic prediction for the Asian summer monsoon precipitation (1983-2011) based on the APCC multimodel system and a statistical model. J Geophys Res 117:D04102. doi:10.1029/ 2011JD016308

Wang B, Xie X (1996) Low-frequency equatorial waves in vertically sheared flows. Part I: stable waves. J Atmos Sci 53:449-467

Wang B, Wu R, Fu X (2000) Pacific-East Asia teleconnection: how does ENSO affect East Asian climate? J Clim 13:1517-1536

Wang B, Wu R, Li T (2003) Atmosphere-Warm Ocean interaction and its impact on Asian-Australian Monsoon variation. J Clim 16:1195-1211

Wang B, Kang IS, Lee JY (2004) Ensemble simulations of AsianAustralian monsoon variability by 11 AGCMs. J Clim $17: 803-818$

Wang B, Ding Q, Fu X, Kang IS, Jin K, Shukla J, Doblas-Reyes F (2005) Fundamental challenge in simulation and prediction of summer monsoon rainfall. Geophy Res Lett 32:L15711

Wang B, Lee JY, Kang IS, Shukla J, Hameed SN, Park CK (2007) Coupled predictability of seasonal tropical precipitation. CLIVAR Exch 12:17-18

Wang B et al (2008a) How accurately do coupled climate models predict the Asian-Australian monsoon interannual variability? Clim Dyn 30:605-619 
Wang B et al (2008b) Interdecadal changes in the major modes of Asian-Australian monsoon variability: strengthening relationship with ENSO since the late 1970s. J Clim 21:1771-1789

Wang B et al (2009a) Advance and prospect of seasonal prediction: assessment of the APCC/CliPAS 14-model ensemble retroperspective seasonal prediction (1980-2004). Clim Dyn 33:93-117. doi:10.1007/s00382-008-0460-0

Wang B, Huang F, Wu Z, Yang J, Fu X, Kikuchi K (2009b) Multiscale climate variability of the South China Sea monsoon: a review. Dyn Atmos Oceans 47:15-37

Wang B, Liu J, Yang J, Zhou T-J, Wu Z (2009c) Distinct principal modes of early and late summer rainfall anomalies in East Asia. J Clim 22:3864-3875

Wang B, Liu J, Kim HJ, Webster PJ, Yim SY, Xiang B (2013a) Northern Hemisphere summer monsoon intensified by mega-El Nino/southern oscillation and Atlantic multidecadal oscillation. PNAS 110:5347-5352

Wang B, Xiang B, Lee JY (2013b) Subtropical high predictability establishes a promising way for monsoon and tropical storm predictions. PNAS 110:2718-2722
Wang B, Yim SY, Lee JY, Liu J, Ha KJ (2014) Future change of Asian-Australian monsoon under RCP4.5 anthropogenic warming scenario. Clim Dyn 42:83-100. doi:10.1007/s00382-0121564-0

Webster PJ, Moore A, Loschnigg J, Leban M (1999) Coupled oceanatmosphere dynamics in the Indian Ocean during 1997-98. Nature 401:356-360

Xiang B, Yu W, Li T, Wang B (2011) The critical role of the boreal summer mean state in the development of the IOD. Geophys Res Lett 38. doi:10.1029/2010GL045851

Xiang B, Wang B, Yu W, Xu S (2013) How can anomalous western North Pacific subtropical high intensify in late summer? Geophys Res Lett. doi:10.1002/grl.50431

Yim SY, Wang B, Xing W (2014) Prediction of early summer rainfall over South China by a physical-empirical model. Clim Dyn. doi:10.1007/s00382-013-2014-3

Yun KS, Seo KH, Ha KJ (2010) Interdecadal change in the relationship between ENSO and the intraseasonal oscillation in East Asia. J Clim 23:3599-3612 